\title{
Numerical limit analysis of keyed shear joints in concrete structures
}

\author{
Herfelt, Morten Andersen; Poulsen, Peter Noe; Hoang, Linh Cao; Jensen, Jesper F.
}

Published in:

Structural Concrete

Link to article, DOI:

$10.1002 /$ suco.201500161

Publication date:

2016

Document Version

Peer reviewed version

Link back to DTU Orbit

Citation (APA):

Herfelt, M. A., Poulsen, P. N., Hoang, L. C., \& Jensen, J. F. (2016). Numerical limit analysis of keyed shear joints in concrete structures. Structural Concrete, 17(3), 481-490. https://doi.org/10.1002/suco.201500161

\section{General rights}

Copyright and moral rights for the publications made accessible in the public portal are retained by the authors and/or other copyright owners and it is a condition of accessing publications that users recognise and abide by the legal requirements associated with these rights.

- Users may download and print one copy of any publication from the public portal for the purpose of private study or research.

- You may not further distribute the material or use it for any profit-making activity or commercial gain

- You may freely distribute the URL identifying the publication in the public portal

If you believe that this document breaches copyright please contact us providing details, and we will remove access to the work immediately and investigate your claim. 


\title{
Numerical limit analysis of keyed shear joints in concrete structures
}

\author{
Morten A. Herfelt*1,2, Peter N. Poulsen ${ }^{2}$, Linh C. Hoang ${ }^{2}$, Jesper F. Jensen ${ }^{1}$ \\ ${ }^{1}$ ALECTIA A/S, Teknikerbyen 34, 2830 Virum, Denmark \\ ${ }^{2}$ Department of Civil Engineering, Technical University of Denmark, Brovej, Building 118, 2800 Kgs. \\ Lyngby, Denmark
}

\begin{abstract}
This paper concerns the shear capacity of keyed joints, which are transversely reinforced with overlapping Ubar loops. It is known from experimental studies that the discontinuity of the transverse reinforcement affects the capacity as well as the failure mode; however, to the best knowledge of the authors, previous theoretical works and present design equations in standards do not account for this important effect. In this paper, a detailed model based on finite element limit analysis is introduced to assess the effect of the discontinuous reinforcement. The model is based on the lower bound theorem and uses the modified Mohr-Coulomb yield criterion, which is formulated for second-order cone programming. The model provides a statically admissible stress field as well as the failure mode. Twenty-four different test specimens are modelled and the calculations are compared to the experimental results. The results of the model show satisfactory agreement with the experimental observations. The model produces significantly better estimates of the shear capacity than the design equations of Eurocode 2.
\end{abstract}

Keywords: shear walls, precast concrete elements, keyed joints, limit analysis, finite element, numerical modelling, plasticity

\section{Introduction}

Precast concrete wall units connected by in-situ cast joints are often used to stabilise building structures against horizontal loads. The efficiency of such wall systems (often referred to as shear walls) is highly

\footnotetext{
${ }^{*}$ Corresponding author. E-mail: mahe@alectia.com

Submitted to Structural Concrete: the journal of the fib.
} 
dependent on the ability of the joints to transfer in-plane shear forces between adjacent precast wall units. The joints are usually designed as so-called keyed joints where U-bar loops protrude from the ends of the precast units and overlap each other in a narrow in-situ cast zone (Fig. 1). A continuous reinforcement bar (locking bar) is typically placed inside the loops to enhance the transfer of tension between pairs of U-bars. Due to the narrow geometry as well as the discontinuity of the reinforcement layout, the joints are most often the weakest parts of a shear wall system; hence, in practice, the shear capacity of the keyed joints is often the governing factor for the load capacity of the entire shear wall.

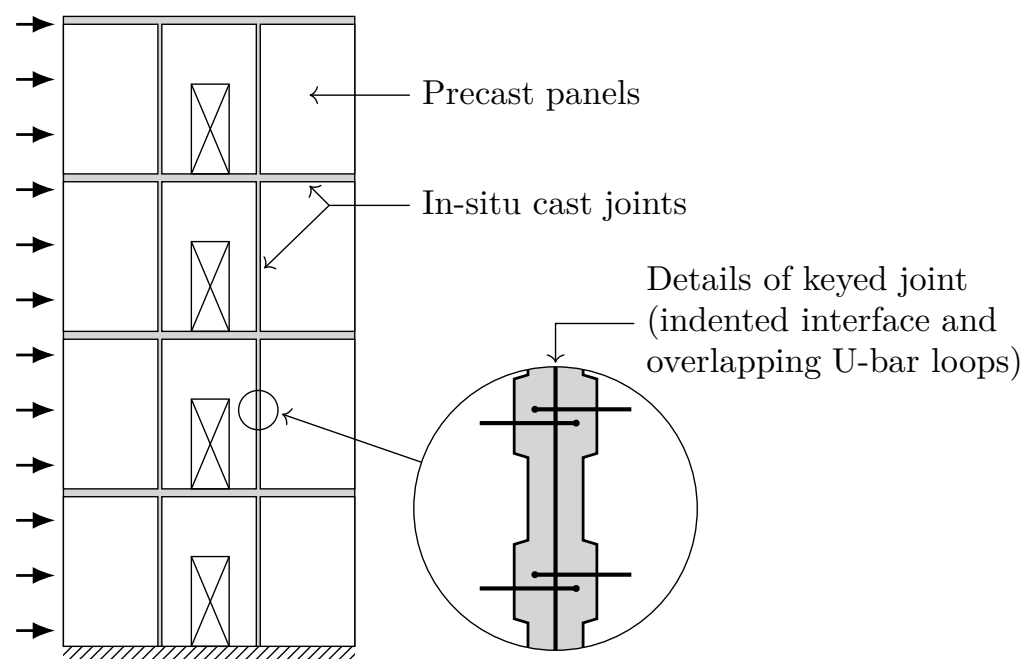

Figure 1: Four storey shear wall constructed from precast units connected by in-situ cast joints.

Several papers on the shear capacity of keyed shear joints were published during the 1970s and 1980s [see e.g. 1-6]. The main body of these works is concentrated on experimental investigations. As a result, only simple and rather primitive empirical design formulas are available in current design standards, including the Eurocode 2 [7]. In attempts to establish simplified mechanical models for the ultimate limit state design of keyed joints, works based on the theory of rigid-plasticity have been presented in the literature. This includes upper bound solutions derived from analysis of failure mechanisms $[8,9]$ as well as lower bound solutions based on strut-and-tie models [9-11], see Fig. 2. Jørgensen et al. [12, 13] also presented several analytical upper bound solutions for similar problems, namely wire loop connections. Common for these plasticity models is that the discontinuity of the transverse reinforcement (i.e. the overlapping U-bars) is not taken into account. This means that depending on the U-bar layout, these models may be too simplified because 
they can neither capture the complex stress field nor the complex failure mechanism developed within the joint. In the end, this will affect the ultimate capacity of the joint.

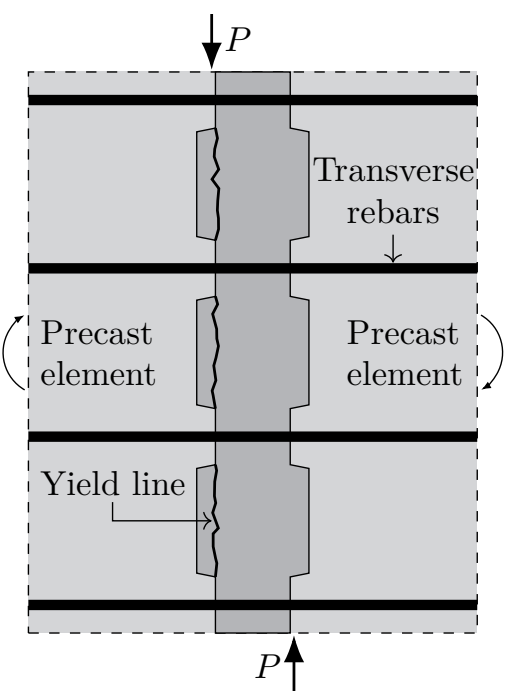

(a)

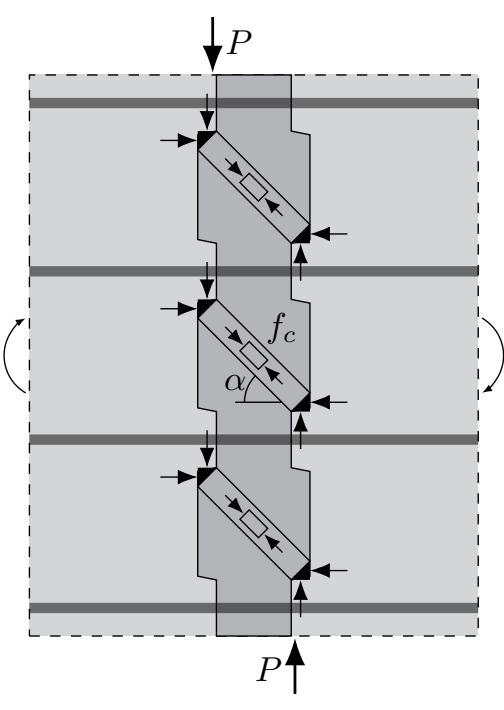

(b)

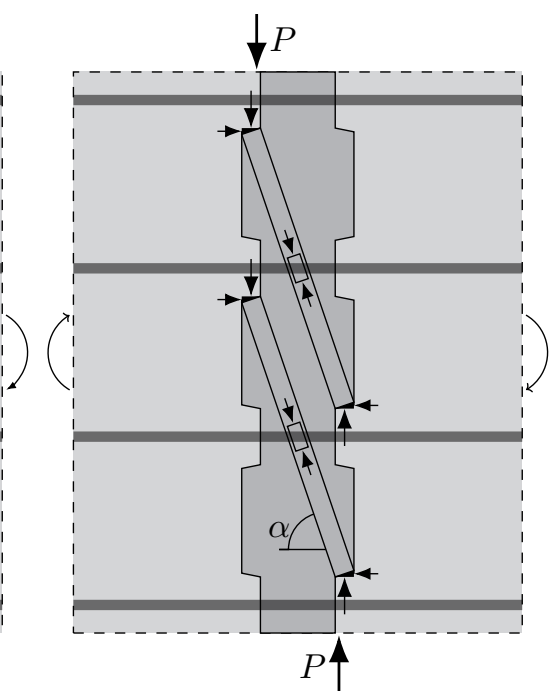

(c)

Figure 2: (a) Simplified failure mechanism $[8,9]$ and $(b, c)$ strut-and-tie models $[9,10]$ for analytical modelling of shear capacity of keyed joints.

In this paper we present a detailed study of the effects of the discontinuous transverse reinforcement on the shear capacity of keyed joints. The study has been carried out by use of numerical rigid-plastic limit analysis. This means that the analysis is based on the same fundamental assumptions as those adopted for the aforementioned upper and lower bound models; however, in numerical limit analysis, the problem is discretized using so-called equilibrium finite elements and subsequently solved as an optimization problem (see Section 2). For this reason, complex stress fields and failure modes can be handled. The results obtained from this study show that the U-bar configuration and particularly the mutual distance between adjacent overlapping U-bars play a dominant role for the ultimate shear capacity. It is demonstrated that the effects captured by the detailed numerical limit analysis correlate well with experimental observations.

To emphasize the context in which this study has been undertaken, it is here necessary to mention that the numerical limit analysis approach has deliberately been chosen instead of a classical incremental non-linear finite element model. The reason is threefold: First, the chosen approach allows the obtained results to be placed in the same context as existing analytical models (i.e. the aforementioned upper and lower bound 
models) and enables direct comparisons. Next, finite element limit analysis is more computationally efficient than incremental non-linear finite element analysis. This is due to the fact that the former approach is only concerned with the load carrying capacity, which is the main objective in practical ultimate limit state design.

Finally, the detailed modelling of keyed joints for finite element limit analysis has to be viewed with a long term research perspective, where the authors are working on development of numerical tools for the ultimate limit state design of entire precast buildings (see Section 6).

\section{Numerical limit analysis}

Numerical limit analysis based on the lower bound theorem of plastic theory can be used to determine statically admissible stress fields, which will give a safe estimate of the load carrying capacity of the structure. The method assumes a rigid plastic material behaviour, where no deformations occur before yielding. The mathematical formulation of the problem consists of a set of equilibrium equations, the yield conditions, and an objective function. Anderheggen and Knöpfel [14] were the first to present the mathematical framework using linear programming to optimise the load carrying capacity. Since the 1970s several researchers have contributed and extended the theory and use of the method [15-19]. Numerical limit analysis is a so-called direct method, i.e. the ultimate load capacity is determined in one step, which is a clear advantage over nonlinear FEM when it comes to practical applications. The general formulation of lower bound load optimisation can be stated as $[17,20]$ :

$$
\begin{array}{ll}
\operatorname{maximise} & \lambda \\
\text { subject to } & \mathbf{H} \boldsymbol{\beta}=\boldsymbol{R} \lambda+\boldsymbol{R}_{0} \\
& f\left(\boldsymbol{\beta}_{i}\right) \leq 0, \quad i=1,2, \ldots, m
\end{array}
$$

The linear equality constraints ensure equilibrium, while the yield functions $f\left(\boldsymbol{\beta}_{i}\right) \leq 0$ ensure that the state of stress does not violate the yield criteria in any point. The load acting on the structure consists of a constant part $\boldsymbol{R}_{0}$ and a scalable part $\boldsymbol{R} \lambda$. The global equilibrium matrix, $\mathbf{H}$, comprises the local contributions from each equilibrium element. $\boldsymbol{\beta}$ is the stress vector. The lower bound problem (1) has a corresponding upper bound problem, which is solved simultaneously, and the solution to the upper bound problem gives the collapse mode of the structure [21].

The yield function $f$ is generally non-linear, but convex; hence, (1) is a convex optimisation problem. In this paper we use the modified Mohr-Coulomb yield criterion, which can be formulated exact using second-order 
cone programming (SOCP), which can be solved remarkably efficient using interior point methods. The problem (1) will be solved by use of the commercial solver MOSEK [22]. For a detailed description of SOCP and interior point algorithms the reader is referred to References [23-25].

\section{$3 \quad$ Keyed joints}

Fig. 3 schematically shows the typical design of a keyed joint where the reinforcement and interfaces are indicated by thick black lines. A local coordinate system $(n, t)$ is used as the reference system. The keys of the interface are defined by the parameters $h_{1}, h_{2}$, and $d$, while the parameters $o$ and $b$ define the overlap of the U-bars and the width of the joint, respectively. Finally, $u$ is the distance between the two U-bars of a pair.

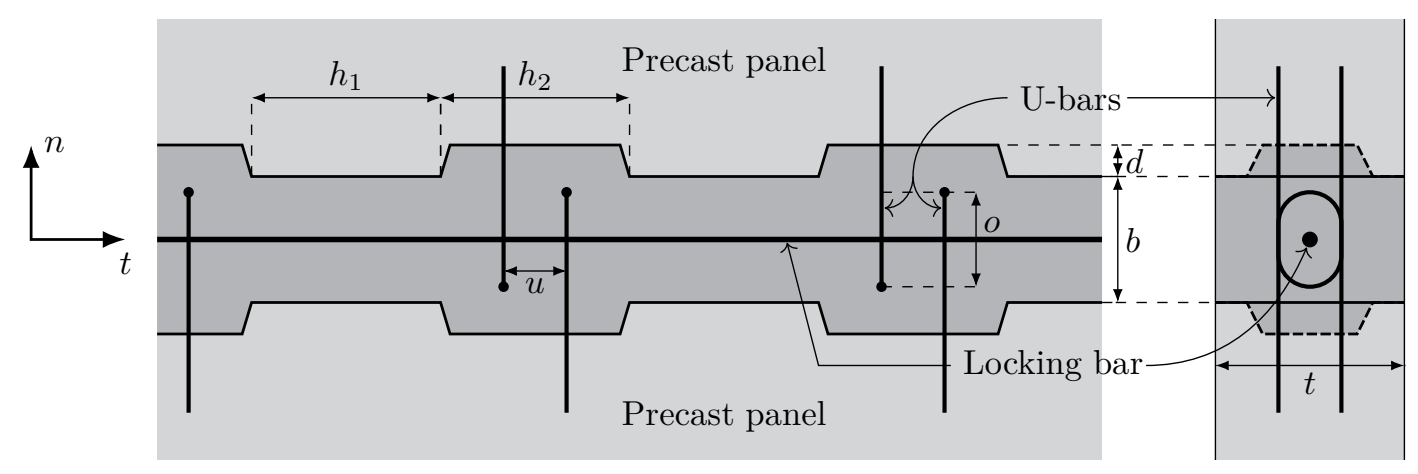

Figure 3: Elevation and cross section of a basic design of a keyed joint reinforced with U-bars.

\section{Equilibrium elements}

Three types of equilibrium elements are required for the detailed model: First, a triangular element with a linear stress variation (LST element) will represent the precast concrete and joint concrete. In this paper we use an enhanced version of the plate element originally developed by Sloan [15] and Poulsen and Damkilde [17]. The enhanced element is developed by Nielsen [26] and a brief description of the element is given in the appendix. The reinforcement can be represented as one-dimensional bars, which is modelled by a bar element developed by Poulsen and Damkilde [17]. The bar element only provides dissipation along its axis and dowel action is neglected. Finally, a suitable interface element is needed to model the casting interface between the precast panels and the joint concrete. 
In this section we present a one-dimensional interface element developed for the detailed model. The interface element has to be compatible with the linear stress variation of the LST element; hence, a linear variation of stresses is also required for the interface element.

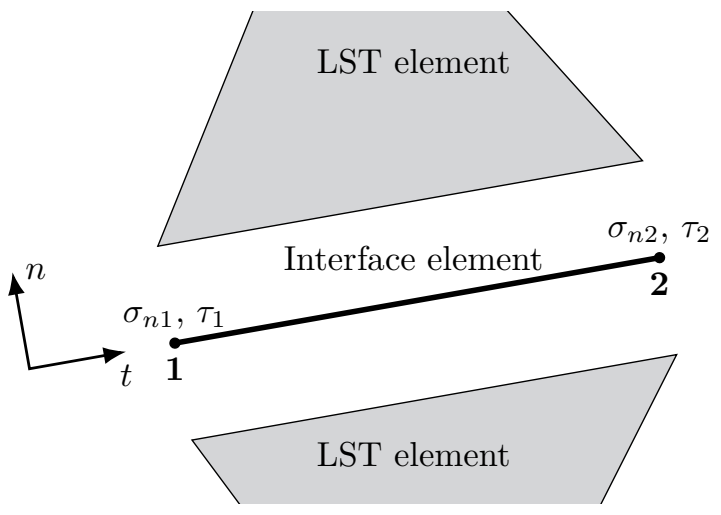

(a)

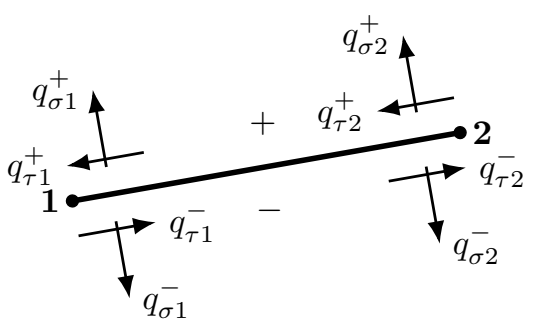

(b)

Figure 4: Interface element: Geometry, local coordinate system and stress variables (a); generalized nodal forces (b).

The interface element has four stress variables as shown in Fig. 4(a) and contributes to 8 equilibrium equations on the global level; see Fig. 4(b). The stresses are simply transferred directly through the interface as seen in the element equilibrium matrix $\mathbf{h}_{e l}$ :

$$
\boldsymbol{q}=\left[\begin{array}{c}
q_{\sigma 1}^{+} \\
q_{\tau 1}^{+} \\
q_{\sigma 2}^{+} \\
q_{\tau 2}^{+} \\
q_{\sigma 1}^{-} \\
q_{\tau 1}^{-} \\
q_{\sigma 2}^{-} \\
q_{\tau 2}^{-}
\end{array}\right]=\left[\begin{array}{cccc}
1 & 0 & 0 & 0 \\
0 & -1 & 0 & 0 \\
0 & 0 & 1 & 0 \\
0 & 0 & 0 & -1 \\
-1 & 0 & 0 & 0 \\
0 & 1 & 0 & 0 \\
0 & 0 & -1 & 0 \\
0 & 0 & 0 & 1
\end{array}\right]\left[\begin{array}{c}
\sigma_{n 1} \\
\tau_{1} \\
\sigma_{n 2} \\
\tau_{1}
\end{array}\right]=\mathbf{h}_{e l} \boldsymbol{\beta}_{e l}
$$

Nielsen and Hoang [10] suggest a suitable yield criterion for interfaces of joints, which corresponds to the modified Mohr-Coulomb yield criterion for plane strain with one free normal stress parameter. The yield envelope is illustrated in Fig. 5. Here, we present the general formulation, which include a separation strength to represent adhesive effects. In practice, the separation strength is not reliable unless the interface is very rough and treated carefully before casting of the joint. In the calculations presented in this paper, 
the separation strength is taken as zero. In principal stresses the yield criterion can be written as:

$$
\begin{gathered}
\sigma_{1} \leq f_{t} \\
k \sigma_{1}-\sigma_{2} \leq 2 c \sqrt{k}
\end{gathered}
$$

where $\sigma_{1}$ and $\sigma_{2}$ are the largest and smallest principal stresses, respectively, $f_{t}$ is the separation strength of the interface, and $c$ is the cohesion. $k$ is a friction parameter defined as $k=\left(\sqrt{\mu^{2}+1}+\mu\right)^{2}$ where $\mu$ is the friction coefficient of the interface. The principal stresses are given as

$$
\left.\begin{array}{l}
\sigma_{1} \\
\sigma_{2}
\end{array}\right\}=\frac{\sigma_{n}+\sigma_{t}}{2} \pm \sqrt{\frac{1}{4}\left(\sigma_{n}-\sigma_{t}\right)^{2}+\tau^{2}}
$$

and $\sigma_{t}$ is the free normal stress. The yield criterion can be formulated as a single quadratic cone and two linear inequalities by introducing three auxiliary variables $[19,27]$.

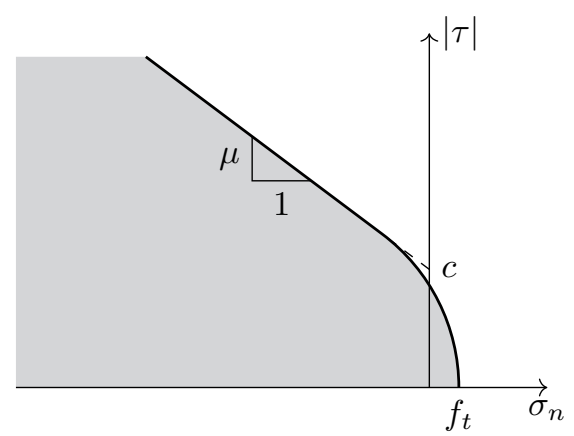

Figure 5: Yield criterion for the interface: The gray region indicates the interior of the yield envelope.

\section{Model and analysis}

This section will present the numerical model and the results, which will be compared to experimental data by Hansen and Olesen [5] and Fauchart and Cortini [2] as well as the design formulas of the Eurocode [7]. The geometry of the 16 test specimens by Hansen and Olesen is given by $h_{1}=h_{2}=40 \mathrm{~mm}, d=6 \mathrm{~mm}$, $b=t=50 \mathrm{~mm}, o=30 \mathrm{~mm}$ (see Fig. 3), $l=1200 \mathrm{~mm}$, and 14 keys. The geometry of the 8 test specimens by Fauchart and Cortini is given by $h_{1}=167 \mathrm{~mm}, h_{2}=83 \mathrm{~mm}, d=20 \mathrm{~mm}, b=145 \mathrm{~mm}, t=90 \mathrm{~mm}, o=115$ $\mathrm{mm}, l=1200 \mathrm{~mm}$, and 4 keys.

Fig. 6 shows a sketch of the numerical model as well as the meshes for the models of the specimens. The loads on the model, i.e. the forces $F_{1}$ and $F_{2}$, ensure that the moment in the centre of the joint is zero, i.e. 


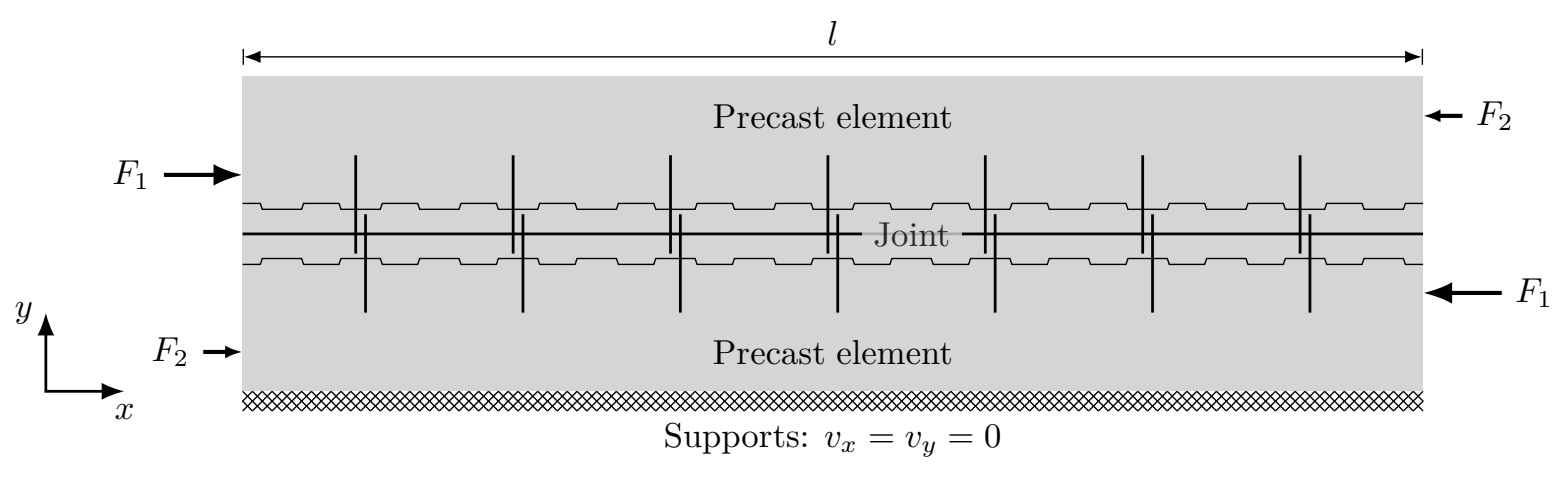

(a)

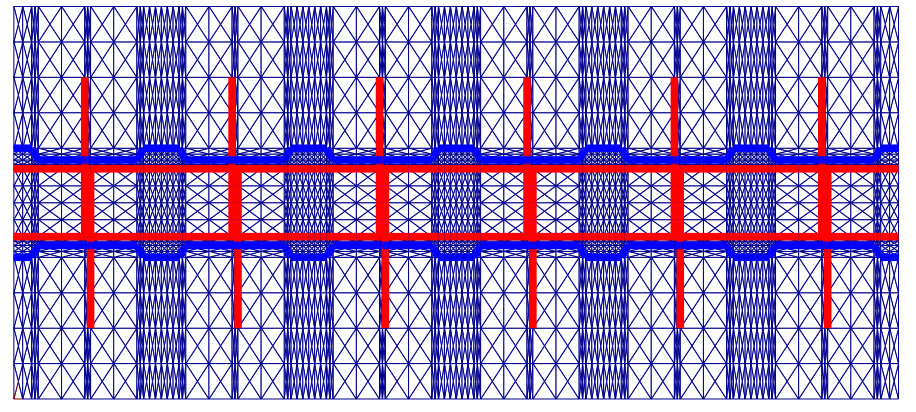

(b)

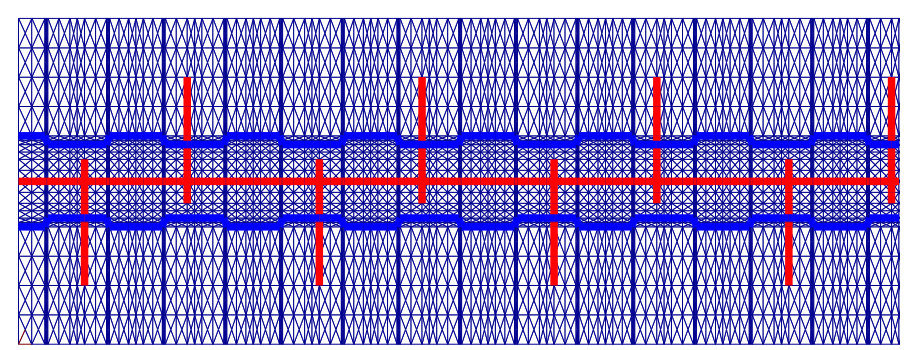

(d)

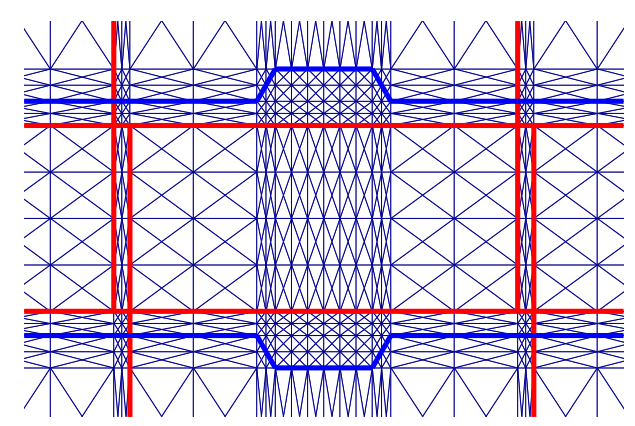

(c)

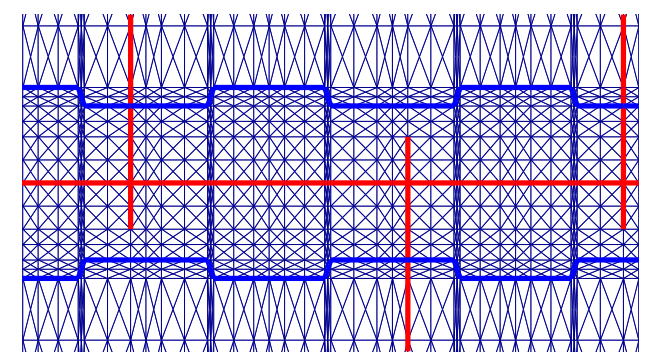

(e)

Figure 6: a) Sketch of the numerical model including boundary conditions and loading; b) mesh for the specimens by Fauchart and Cortini (8064 elements); c) zoom of the mesh seen in b) showing the keyed interface, two pairs of U-bars (thick vertical lines), and two locking bars (thick, straight horizontal lines), d) half of the mesh for the specimens by Hansen and Olesen (20014 elements); e) zoom of the mesh seen in d) showing the keyed interface, a locking bar (thick horizontal line), and a pair of U-bars (thick vertical lines). 
pure shear. The joint concrete is modelled using Mohr-Coulomb yield criterion for plane stress conditions. Near the U-bar loops, the concrete will be in a triaxial stress state; hence, the assumption of plane stress condition is conservative in those regions. The tensile strength of the joint concrete is neglected $\left(f_{t}=0\right)$ and the effectiveness factor is chosen as $\nu=1$, which is the same value adopted for the lower bound strutand-tie model by Nielsen and Hoang [10]. It should be mentioned that Jørgensen et al. [12, 13] adopted a $\nu$-factor smaller than unity for looped joints; however, the models by Jørgensen et al. are upper bound models which take into account plane strain conditions as well as the triaxial stress state locally at the loops. Most probably, the best estimate of the $\nu$-factor would be somewhere between unity and the value used by Jørgensen et al. Determination of such an estimate would require development of a 3D numerical model that can be calibrated with tests, which are heavily reinforced with U-bars. As mentioned in Section 4, the capacity of the interface is defined by the cohesion, the friction coefficient, and the separation strength. For smooth surfaces, the cohesion is very sensitive to curing and may be taken as $c=0.55 \sqrt{f_{c}}$ provided that cracking (e.g. due to shrinkage) has not taken place [10]. For the numerical model, a cohesion of 0 to $0.5 \mathrm{MPa}$ gives the best results indicating that shrinkage cracking indeed has taken place. The interface is assumed to be smooth and a friction coefficient of $\mu=0.75$ can be used here [10, 28]. Finally, a separation strength of $f_{t}=0$ is used for the interface elements in all models.

\subsection{Comparison and analysis}

The experimental results by Hansen and Olesen [5] and Fauchart and Cortini [2] are compared to the numerical model and the Eurocode 2 [7]. We define the mechanical reinforcement ratio $\Phi$ as follows:

$$
\Phi=\frac{\sum A_{s U} f_{y}}{t l f_{c}}
$$

i.e. the total yield force in the U-bars over the total area times the compressive strength of the joint concrete. According to the Eurocode 2, the shear capacity of a keyed joint can be computed as

$$
\tau=\min \left\{\begin{array}{l}
c f_{t} A_{k e y} /(t l)+\mu \Phi f_{c} \\
\frac{1}{2} \nu f_{c} A_{k e y} /(t l)
\end{array}\right.
$$

where $A_{k e y}$ is the total area of the keys, $f_{t}$ is the tensile strength, and $c$ is a parameter that relates the tensile strength to the cohesion. For keyed joints the following values are used; $\mu=0.9$ and $c=0.5$. The tensile strength is taken as $f_{t}=0.21 f_{c}^{2 / 3}$. In Eurocode 2, the effectiveness factor $\nu$ used for beam shear problems 
is also used for shear in joints, i.e. $\nu=0.7-f_{c} / 200\left(f_{c}\right.$ in MPa $)$.

It is important to emphasise that mean values of material parameters have been used for the comparison.

When the numerical model is used for design, however, relevant partial safety coefficients prescribed by codes (e.g. the Eurocodes) must be introduced. In this context, it may be useful to mention that the design value for the cohesion of the interfaces should be determined by adopting a partial safety coefficient, $\gamma_{c}$, that is related to the tensile strength of the concrete (and not the compressive strength).

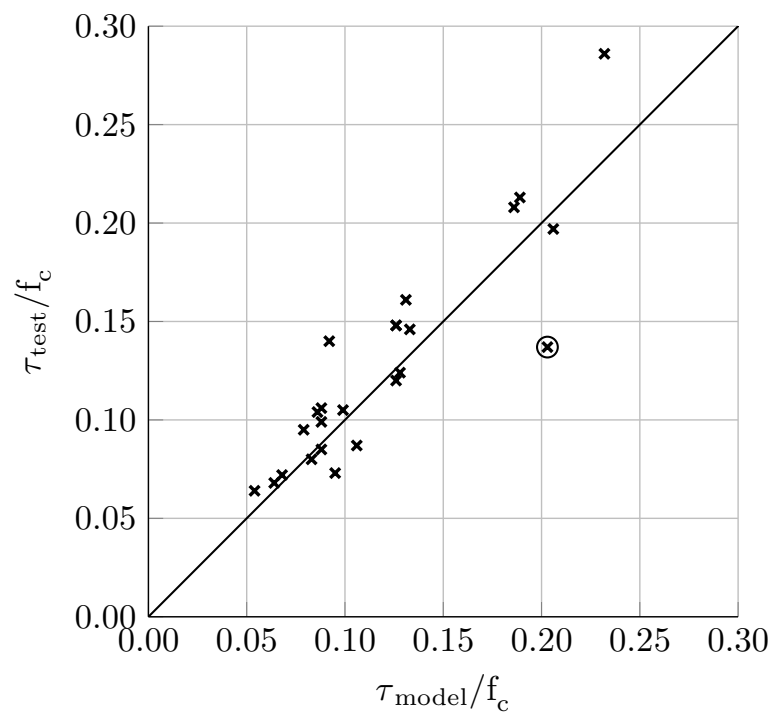

Figure 7: Numerical results compared to a total of 24 experiments by Hansen and Olesen [5] and Fauchart and Cortini [2].

Fig. 7 shows that the numerical model is capable of predicting a good estimate of the load carrying capacity for a wide range of experiments. In average, the model predicts shear capacities slightly below the experimental results, but for a single experiment (specimen 29, indicated by a circle in Fig. 7) the model overestimates the capacity by a significant margin. It is worth noting that specimen 29 is the only specimen for which the Eurocode overestimates the shear capacity (see Fig. 8(a) and Tab. 1).

Fig. 8(a) shows that the Eurocode generally underestimates the capacity of the joint; in some cases by almost $60 \%$. The numerical model predicts a higher shear capacity than the Eurocode formulas as seen in Fig. 8(b). It is important to emphasise that the difference in the two adopted values for $\nu$ only affects a minority of the experiments, namely specimens 28 and 29 by Hansen and Olesen [5] and specimens 8 and 12 by Fauchart 


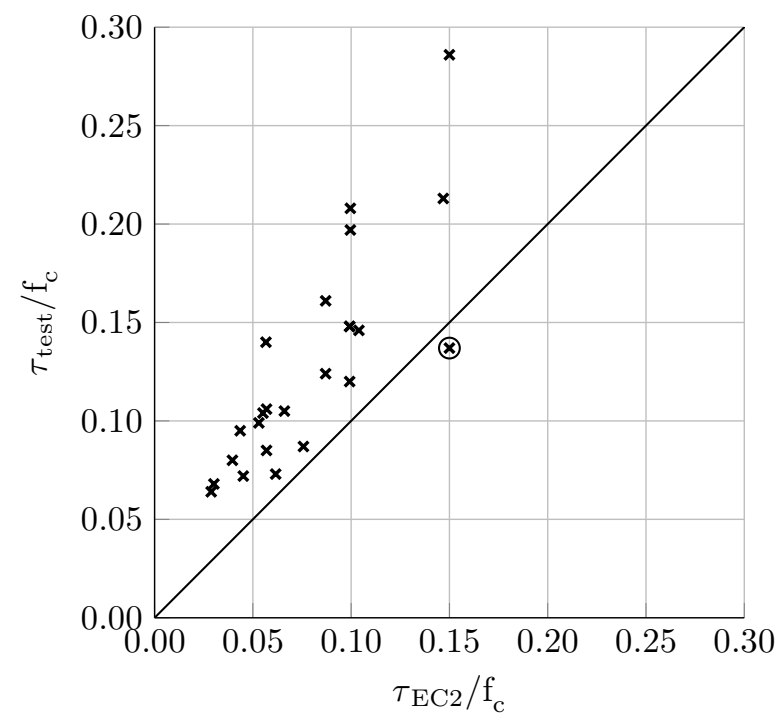

(a)

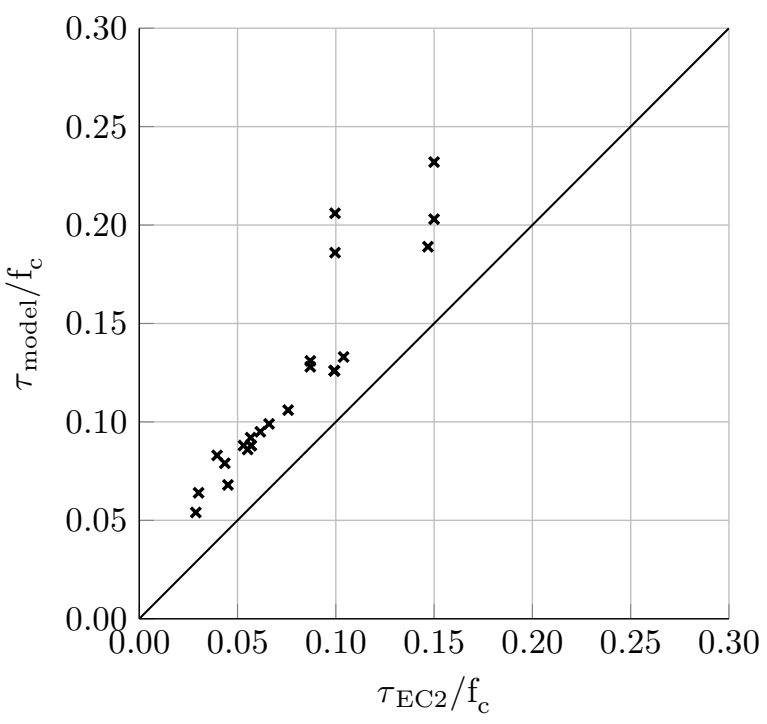

(b)

Figure 8: (a) Design formulas of the Eurocode compared to experimental results; (b) design formulas of the Eurocode compared to the results of the numerical model.

and Cortini [2], where the second equation in (5) is governing. All results as well as compressive concrete strength, reinforcement ratio, and distance between the U-bars are given in Tab. 1 and 2. The average error for the numerical model is $-4.3 \%$, while the average error is $-37.9 \%$ for the Eurocode. The error shown in the tables are computed as:

$$
\epsilon_{\text {model }}=\frac{\tau_{\text {model }}-\tau_{\text {test }}}{\tau_{\text {test }}}, \quad \text { and } \quad \epsilon_{E C 2}=\frac{\tau_{E C 2}-\tau_{\text {test }}}{\tau_{\text {test }}}
$$

Specimens 01, 02, 03, 04, 05, 12, 13, 14, 18, and 29 listed in Tab. 1, did not have any transverse reinforcement (U-bars); instead external confinement pressure was applied: For these tests, a reinforcement ratio equivalent to the confinement is listed in the table. It is worth noting that specimen 29 is the only specimen in that group with an equivalent reinforcement ratio larger than 0.10 , but the specimen has a rather low capacity; similar to the capacity of specimens 12 and 13, which have equivalent reinforcement ratios of 0.43 and 0.95 , respectively.

As Tab. 1 shows, two of the specimens, 24 and 26, have a large value of $u$. It is seen that the numerical model produces a very good estimate of the shear capacity for these two specimens compared to the Eurocode. Specimen 25 is identical to specimen 26 except for the reinforcement layout; Fig. 9 and 10 shows the 
distribution of the lowest principal stress and the collapse mode of the two specimens.

The thick blue lines in Fig. 9(a) and 10(a) indicate the interface between the precast panels and the joint concrete, and the thick red lines indicate the reinforcement, i.e. U-bars and locking bar. The deformed reinforcement is plotted by interpolating the placement of the nodes in the deformed mesh. The reinforcement is indicated in Fig. 9(b) and 10(b) by thick gray lines.

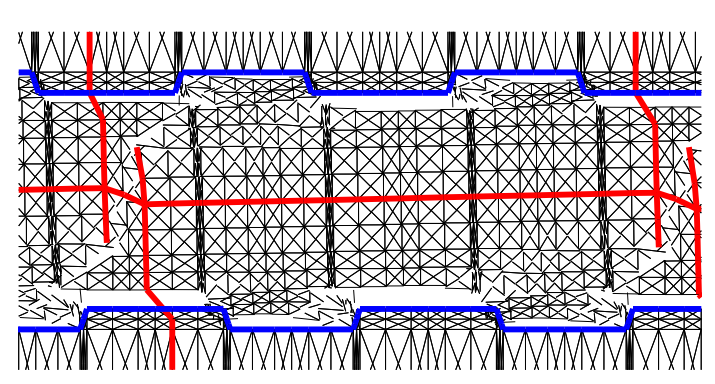

(a)

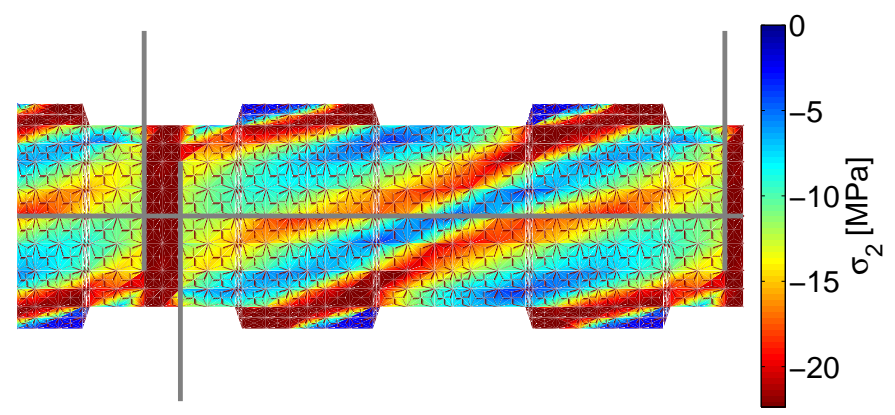

(b)

Figure 9: Collapse mode (a) and lowest principal stress (b) for specimen 25 by Hansen and Olesen [5].

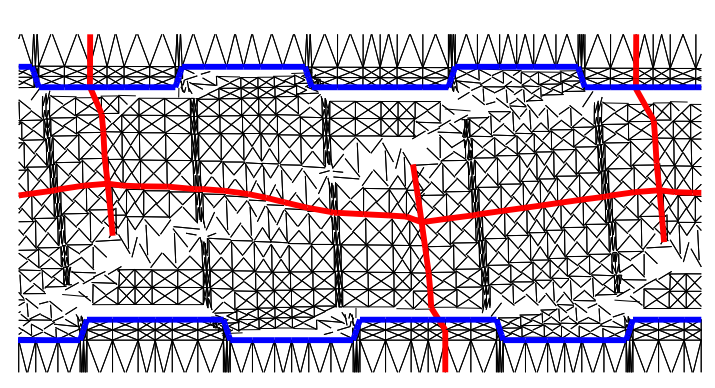

(a)

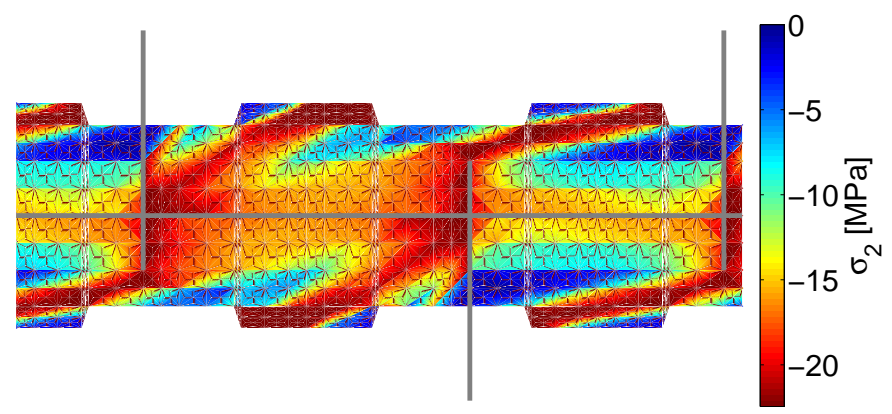

(b)

Figure 10: Collapse mode (a) and lowest principal stress (b) for specimen 26 by Hansen and Olesen [5].

Hansen and Olesen reported that specimen 23, 25, and 27 failed by shearing off the keys of the joint concrete, while for specimen 24 and 26 the core of the joint was almost completely destroyed. The numerical model captures this as illustrated in Fig. 9(a) and 10(a): The keys are partially sheared off for specimen 25, while specimen 26 fails by a diagonal yield zone through the core of the joint. Fig. 9(b) and 10(b) show likewise that the reinforcement layout has a significant influence on the distribution of stresses within the joint: The model of specimen 25 shows distinct diagonal struts throughout the entire core of the joint, while this pattern 
is disrupted by the reinforcement layout in the model of specimen 26 . It is noted that the collapse mode and the stress field observed in Fig. 9 are similar to the simplified failure mechanism and the strut-and-tie models shown in Fig. 2; however, this is not the case for specimen 26 (Fig. 10) where the large distance between the overlapping U-bars alters the load path and collapse mode. In both cases, the diagonal struts tend to end and start at the corners of the shear keys. This indicates that direct strut action carries the majority of the load and the shear capacity is not that sensitive to the interface friction coefficient.

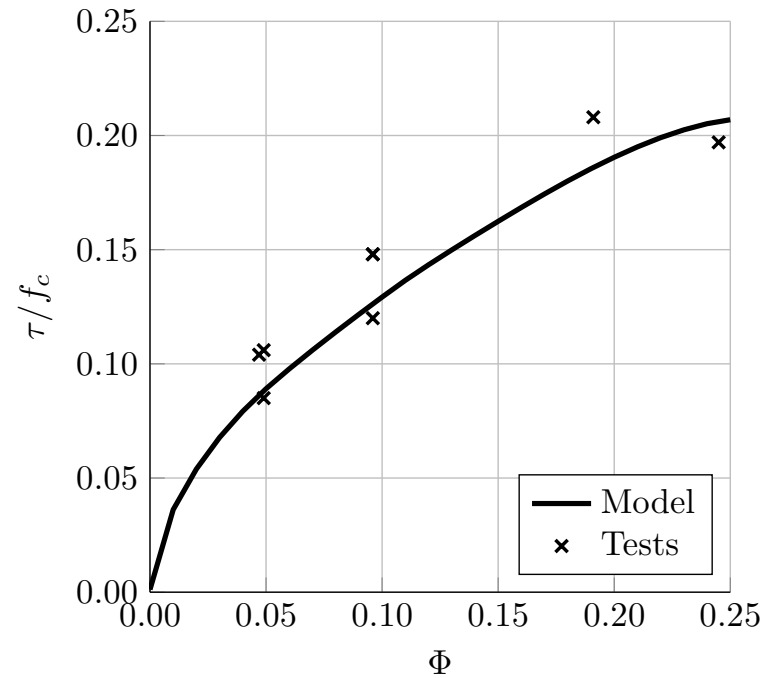

(a) Tests by Fauchart and Cortini [2]

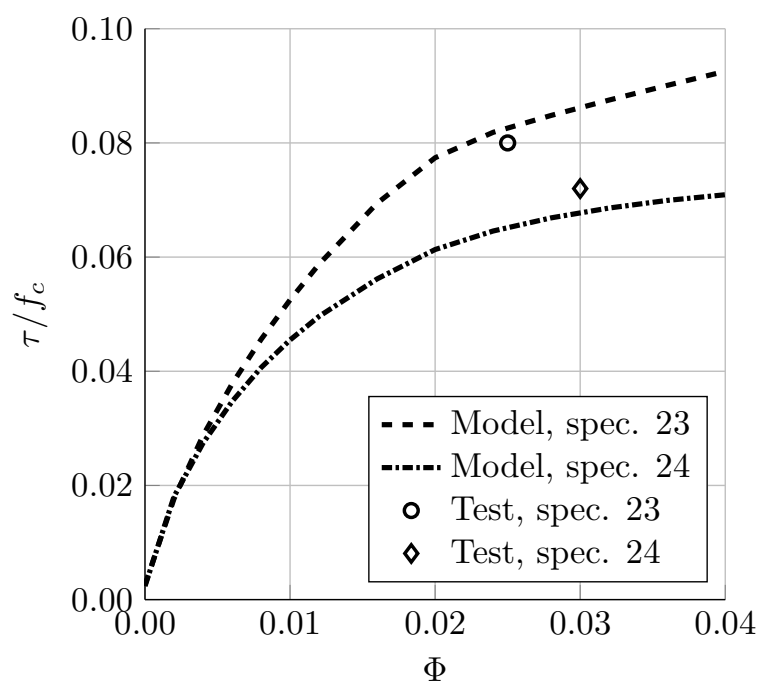

(c) Specimens 23 and 24; Hansen and Olesen [5]

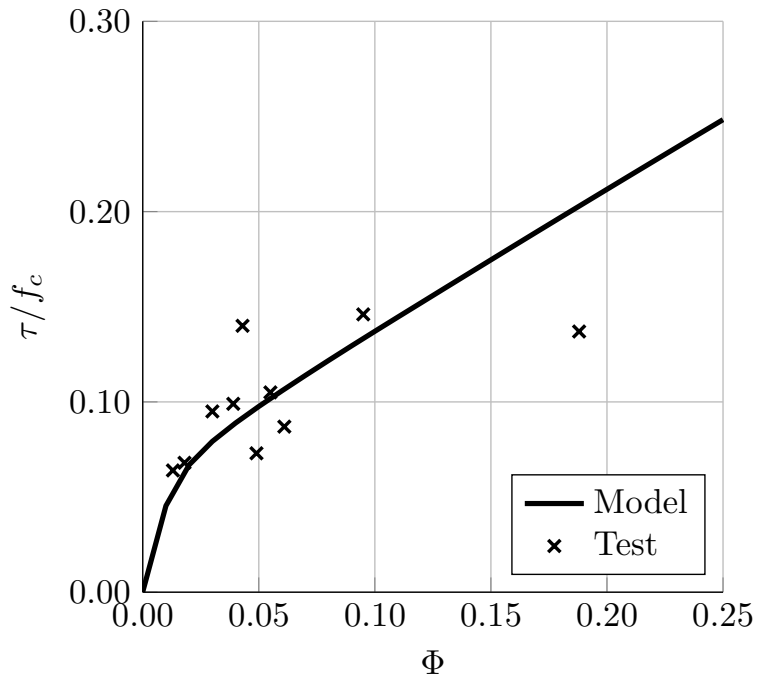

(b) Specimens 01, 02, 03, 04, 05, 12, 13, 14, 18, and 20; Hansen and Olesen [5]

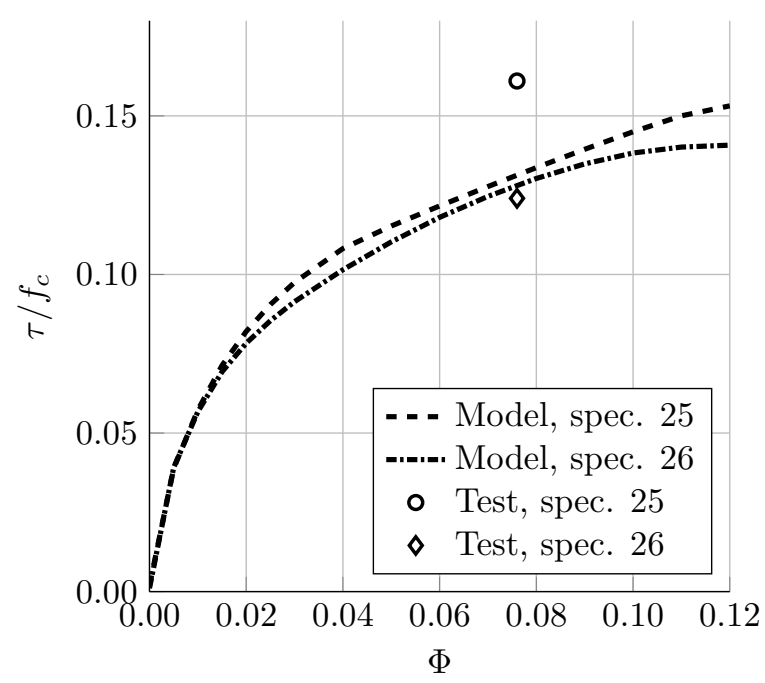

(d) Specimens 25 and 26; Hansen and Olesen [5]

Figure 11: Capacity curves for various specimens and reinforcement layouts. 
Fig. 11 shows the shear capacity as a function of the mechanical reinforcement ratio for the different specimens: In the calculations, the reinforcement ratio of the transverse reinforcement is simply varied by adjusting the yield strength of the U-bars. The detailed model provides an excellent estimate of the capacity of the experiments by Fauchart and Cortini [2] as illustrated in Fig. 11(a). Likewise, Fig. 11(b) shows that the model gives a reasonable estimate for the specimens without transverse reinforcement by Hansen and Olesen [5] despite the somewhat scattered data. Fig. 11(c) and (d) clearly illustrate the effect of the reinforcement layout; namely that the shear capacity decreases, even for low reinforcement ratios, when the distance between overlapping U-bars increases.

\section{$6 \quad$ Future work}

A detailed model for numerical limit analysis provides unique insights into the ultimate behaviour of keyed joints and may in practice be used to optimise the joint layout, i.e. the geometry of shear keys and the position of overlapping U-bars. Such a task is important and relevant for producers of precast concrete elements, for whom optimisation of design details is often motivated by the fact that any benefits gained will be accumulated over time because of mass production. On the other hand, for consulting engineers working with design and calculations of entire building structures, it is not feasible to aim for a level of detail similar to the model presented in this paper. It is simply too time consuming to work with global models of entire structures (e.g. the four storey shear wall shown in Fig. 1) where all joints are modelled in details. In global finite element models, each of the precast wall units should only be modelled by use of a limited number of the aforementioned LST elements in order to reduce computational memory requirements and CPU time. This has the consequence that the keyed joints have to be modelled by one-dimensional equilibrium elements that are compatible with the LST element. Hence, to enable numerical limit analysis of entire structures in the future, it is necessary to develop a one-dimensional element to model the keyed shear joints. This, in fact, is an ongoing task by the authors and the primary challenge here is to develop a computational efficient element, which is able to reflect some of the important features of a keyed shear joint. Thus, in this context, the detailed model presented in this paper will be used for benchmarking and comparison. Finally, the authors are currently using the detailed numerical model to carry out an extensive parameter study with the aim of developing a set of simple design equations which will make it possible to account for the effect 
of the discontinuous reinforcement. These design formulas are thought of as an extension of the formulas of the Eurocode.

\section{Conclusions}

The mathematical framework for limit analysis of keyed shear joints based on a rigid plastic material model has been presented. A new equilibrium element representing concrete-concrete interfaces was proposed and a detailed finite element limit analysis model for keyed joints between precast concrete panels has been introduced. The model is formulated for second-order cone programming; a class of convex optimisation problems that can be solved efficiently using interior point methods. The numerical model has been compared to experimental results as well as the design formulas of the Eurocode. A satisfactory correlation between the numerical model and experiments was found with an average error of $-4.3 \%$. The model provides a much better estimate of the load carrying capacity than the design formulas of the Eurocode, which had an average error of $-37.9 \%$. Most importantly, the model also captures the effects of the discontinuous layout of the transverse reinforcement. The results showed that the critical mechanisms and the stress fields within the joint are highly dependent on the mutual distance between overlapping U-bars. The approach presented in this paper may with benefit be used to optimise the shear key layout at the boundaries of mass produced precast wall units as well as the position of the U-bars in the units.

\section{Acknowledgement}

The authors would like to thank the ALECTIA Foundation and Innovation Fund Denmark for financial support of the research presented in this paper.

\section{Appendix: Enhanced linear stress triangle}

The formulation presented here is based on the work of Nielsen [26]. The enhanced linear stress triangle incorporates three subelements, each with a linear stress variation. Several of the variables can be eliminated which reduces the problem size significantly.

A center node divide the element into three subelements as seen in Fig. 12 and $\boldsymbol{\beta}_{1}^{S}$ is the stress vector associated with this center node. $\boldsymbol{\beta}_{i}$ contains the stress variables associated with corner $i$, and $\boldsymbol{\beta}_{C}$ collects 


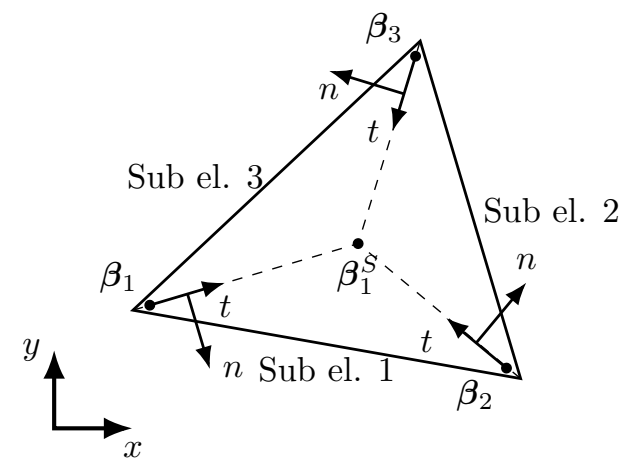

Figure 12: Subelements, stress variables, and local coordinate systems of the enhanced plate element. Dashed lines indicate subelement boundaries.

all stress variables of the corners:

$$
\begin{aligned}
& \boldsymbol{\beta}_{C}=\left[\begin{array}{lll}
\boldsymbol{\beta}_{1}^{T} & \boldsymbol{\beta}_{2}^{T} & \boldsymbol{\beta}_{3}^{T}
\end{array}\right]^{T}, \\
& \boldsymbol{\beta}_{i}=\left[\begin{array}{llll}
\sigma_{n i} & \tau_{n t i} & \sigma_{t i}^{-} & \sigma_{t i}^{+}
\end{array}\right]^{T}, \quad i=1,2,3 \\
& \boldsymbol{\beta}_{1}^{S}=\left[\begin{array}{lll}
\sigma_{x}^{S} & \sigma_{y}^{S} & \tau_{x y}^{S}
\end{array}\right]^{T}
\end{aligned}
$$

The tractions on two opposing boundaries must be in equilibrium; thus, only four stress variables are necessary to describe the stress state in a corner since they are given in local coordinates of the subelement boundary: Only the normal stress in the $t$-direction is discontinuous. Equilibrium on the local level can be stated as

$$
\boldsymbol{q}_{e l}=\mathbf{h}_{e l} \boldsymbol{\sigma}_{e l}=\mathbf{h}_{e l} \mathbf{T}_{e l} \boldsymbol{\beta}_{e l}
$$

where

$$
\mathbf{T}_{e l}=\left[\begin{array}{ll}
\mathbf{T}_{C} & \\
& \mathbf{T}_{S}
\end{array}\right] \quad \text { and } \quad \boldsymbol{\beta}_{e l}=\left[\begin{array}{c}
\boldsymbol{\beta}_{C} \\
\boldsymbol{\beta}_{1}^{S}
\end{array}\right]
$$

$\mathbf{h}_{e l}$ is the local equilibrium for the basic linear stress triangle [see 15, 17], and $\boldsymbol{q}_{e l}$ is the generalised nodal forces, i.e. the contribution to the global equilibrium equations. $\boldsymbol{\sigma}_{e l}$ contains 27 stress variables in global coordinates, 9 for each subelement. $\mathbf{T}_{C}$ transforms the local stress variables of the corners to global coordinates, which can be written as:

$$
\begin{aligned}
& \sigma_{x}=\sigma_{n} n_{x}^{2}+\sigma_{t}^{ \pm} n_{y}^{2}-2 \tau_{n t} n_{x} n_{y} \\
& \sigma_{y}=\sigma_{n} n_{y}^{2}+\sigma_{t}^{ \pm} n_{x}^{2}+2 \tau_{n t} n_{x} n_{y} \\
& \tau_{x y}=\sigma_{n} n_{x} n_{y}-\sigma_{t}^{ \pm} n_{x} n_{y}+\tau_{n t}\left(n_{x}^{2}-n_{y}^{2}\right)
\end{aligned}
$$


where $n=\left[\begin{array}{ll}n_{x} & n_{y}\end{array}\right]^{T}$ is the normal to the subelement boundary through the given corner. Eq. (7) gives the contributions to $\mathbf{T}_{C}$. In the central node $S$, equilibrium across the boundaries between the subelements gives the following equations:

$$
\mathbf{T}_{1}^{x y}\left(\boldsymbol{\beta}_{3}^{S}-\boldsymbol{\beta}_{1}^{S}\right)=0, \quad \mathbf{T}_{2}^{x y}\left(\boldsymbol{\beta}_{1}^{S}-\boldsymbol{\beta}_{2}^{S}\right)=0, \quad \mathbf{T}_{3}^{x y}\left(\boldsymbol{\beta}_{2}^{S}-\boldsymbol{\beta}_{3}^{S}\right)=0
$$

where $\boldsymbol{T}_{i}^{x y}$ is the stress to traction transformation matrix defined as:

$$
\mathbf{T}_{i}^{x y}=\left[\begin{array}{ccc}
n_{x} & 0 & n_{y} \\
0 & n_{y} & n_{x}
\end{array}\right]
$$

These equations can be organised as a linear system

$$
\left[\begin{array}{c:cc}
-\mathbf{T}_{1}^{x y} & \mathbf{0} & \mathbf{T}_{1}^{x y} \\
\mathbf{T}_{2}^{x y} & -\mathbf{T}_{2}^{x y} & \mathbf{0} \\
\mathbf{0} & \mathbf{T}_{3}^{x y} & -\mathbf{T}_{3}^{x y}
\end{array}\right]\left[\begin{array}{c}
\boldsymbol{\beta}_{1}^{S} \\
\boldsymbol{\beta}_{2}^{S} \\
\boldsymbol{\beta}_{3}^{S}
\end{array}\right]=\left[\begin{array}{ll}
\boldsymbol{T}_{1} & \boldsymbol{T}_{23}
\end{array}\right]\left[\begin{array}{c}
\boldsymbol{\beta}_{1}^{S} \\
\boldsymbol{\beta}_{2}^{S} \\
\boldsymbol{\beta}_{3}^{S}
\end{array}\right]=\mathbf{0}
$$

(8) also implicitly defines $\mathbf{T}_{1}$ and $\mathbf{T}_{23}$ as:

$$
\mathbf{T}_{1}=\left[\begin{array}{c}
-\mathbf{T}_{1}^{x y} \\
\mathbf{T}_{2}^{x y} \\
\mathbf{0}
\end{array}\right], \quad \mathbf{T}_{23}=\left[\begin{array}{cc}
\mathbf{0} & \mathbf{T}_{1}^{x y} \\
-\mathbf{T}_{2}^{x y} & \mathbf{0} \\
\mathbf{T}_{3}^{x y} & -\mathbf{T}_{3}^{x y}
\end{array}\right]
$$

$\boldsymbol{\beta}_{2}^{S}$ and $\boldsymbol{\beta}_{3}^{S}$ can now be written as:

$$
\left[\begin{array}{c}
\boldsymbol{\beta}_{2}^{S} \\
\boldsymbol{\beta}_{3}^{S}
\end{array}\right]=-\boldsymbol{T}_{23}^{-1} \boldsymbol{T}_{1} \boldsymbol{\beta}_{1}^{S}
$$

and $\boldsymbol{T}_{S}$ (see Eq. (6)), can be defined as follows:

$$
\left[\begin{array}{c}
\boldsymbol{\beta}_{1}^{S} \\
\boldsymbol{\beta}_{2}^{S} \\
\boldsymbol{\beta}_{3}^{S}
\end{array}\right]=\left[\begin{array}{c}
\mathbf{I} \\
-\boldsymbol{T}_{23}^{-1} \boldsymbol{T}_{1}
\end{array}\right] \boldsymbol{\beta}_{1}^{S}=\boldsymbol{T}_{S} \boldsymbol{\beta}_{1}^{S}
$$

\section{References}

[1] Cholewicki A. Loadbearing Capacity and Deformability of Vertical Joints in Structural Walls of Large Panel Buildings. Building Science. 1971;6:163-184.

[2] Fauchart J, Cortini P. Étude expérimentale de joints horizontaux entre panneaux préfabriqués pour murs de batiments. Annales de L'Institut Technique du Batiment et dês Travaux Publics. 1972;300:86-103.

[3] Bhatt P. Influence of Vertical Joints on Behaviour of Precast Shear Walls. Building Science. 1973;8:221224. 
[4] Bljuger F. Determination of Deformability Characteristics of Vertical Shear Joints in Precast Buildings. Building and Environment. 1976;11:277-282.

[5] Hansen K, Olesen SO. SBI-Report 97: Keyed Shear Joints. Statens Byggeforskningsinstitut; 1976.

[6] Rizkalla SH, Serrette RL, Heuvel JS, Attiogbe EK. Multiple shear key connections for precast shear wall panels. Prestressed Concrete Institute; 1989.

[7] European Committee for Standardization. EN 1992-1-1 Eurocode 2: Design of concrete structures - Part 1-1: General rules and rules for buildings. CEN; 2005.

[8] Jensen BC. On the ultimate load of vertical, keyed shear joints in large panel buildings. In: Symposium on Bearing Walls in Warsaw. vol. 8; 1975. p. 13th.

[9] Christoffersen J. Ultimate Capacity of Joints in Precast Large Panel Concrete Buildings. Technical University of Denmark; 1997.

[10] Nielsen MP, Hoang LC. Limit Analysis and Concrete Plasticity, Third Edition. Taylor \& Francis; 2010.

[11] fib bulletin 43. Structural connections for precast concrete buildings. fédération internationale du béton (fib); 2008.

[12] Jørgensen H. Strength of Loop Connections between Precast Concrete Elements: Part I: U-bar Connections Loaded in Combined Tension and Bending -Part II: Wire Loop Connections Loaded in Shear. University of Southern Denmark - Faculty of Engineering; 2014.

[13] Jørgensen HB, Hoang LC. Load carrying capacity of keyed joints reinforced with high strength wire rope loops. In: Proceedings of the fib Symposium Copenhagen 2015; 2015. .

[14] Anderheggen E, Knöpfel H. Finite element limit analysis using linear programming. International Journal of Solids and Structures. 1972;8:1413-1431.

[15] Sloan SW. Lower Bound Limit Analysis Using Finite Elements and Linear Programming. International Journal for Numerical and Analytical Methods in Geomechanics. 1988;12:61-77. 
[16] Sloan SW. Upper Bound Limit Analysis Using Finite Elements and Linear Programming. International Journal for Numerical and Analytical Methods in Geomechanics. 1989;13:263-282.

[17] Poulsen PN, Damkilde L. Limit State Analysis of Reinforced Concrete Plates Subjected to In-plane Forces. International Journal of Solids and Structures. 2000;37:6011-6029.

[18] Makrodimopoulos A, Martin C. Lower bound limit analysis of cohesive-frictional materials using secondorder cone programming. International Journal for Numerical Methods in Engineering. 2006;66(4):604634.

[19] Krabbenhøft K, Lyamin A, Sloan S. Formulation and solution of some plasticity problems as conic programs. International Journal of Solids and Structures. 2007;44(5):1533-1549.

[20] Krabbenhoft K, Damkilde L. A general non-linear optimization algorithm for lower bound limit analysis. International Journal for Numerical Methods in Engineering. 2003;56(2):165-184.

[21] Krenk S, Damkilde L, Høyer O. Limit analysis and optimal design of plates with equilibrium elements. Journal of Engineering Mechanics. 1994;120:1237-1254.

[22] MOSEK ApS. The MOSEK optimization toolbox for MATLAB manual. Version 7.1 (Revision 33); 2015. Available from: https://www.mosek.com/.

[23] Boyd SP, Vandenberghe L. Convex Optimization. Cambridge University Press; 2004.

[24] Andersen ED, Roos C, Terlaky T. On implementing a primal-dual interior-point method for conic quadratic optimization. Mathematical Programming. 2003;95(2):249-277.

[25] Alizadeh F, Goldfarb D. Second-order cone programming. Mathematical programming. 2003;95(1):3-51.

[26] Nielsen LO. Computational ideal cone plasticity. Part 2: The 2D stress structure; 2014. Technical University of Denmark, Department of Civil Engineering, U-093.

[27] Bisbos C, Pardalos P. Second-order cone and semidefinite representations of material failure criteria. Journal of Optimization Theory and Applications. 2007;134(2):275-301. 
[28] Dahl KKB. Construction joints in normal and high strength concrete. Department of structural Engineering, Technical University of Denmark; 1994. R-311. 
Table 1: Data and results of experiments by Hansen and Olesen [5], the numerical model, and Eurocode 2.

\begin{tabular}{ccccccccc}
\hline & $f_{c}$ & $\Phi$ & $u$ & Experimental & \multicolumn{2}{c}{ Numerical } & \multicolumn{2}{c}{ Eurocode 2 } \\
Specimen & {$[\mathrm{MPa}]$} & {$[-]$} & $\mathrm{mm}$ & $\tau / f_{c}$ & $\tau / f_{c}$ & Error [\%] & $\tau / f_{c}$ & Error [\%] \\
\hline 01 & 29 & 0.013 & - & 0.064 & 0.053 & -17.2 & 0.029 & -55.0 \\
02 & 32 & 0.030 & - & 0.095 & 0.079 & -16.8 & 0.044 & -54.2 \\
03 & 32 & 0.055 & - & 0.105 & 0.102 & -2.9 & 0.066 & -37.1 \\
04 & 16 & 0.061 & - & 0.087 & 0.107 & 23.0 & 0.076 & -13.0 \\
05 & 53 & 0.018 & - & 0.068 & 0.064 & -5.9 & 0.030 & -55.6 \\
12 & 25 & 0.043 & - & 0.140 & 0.092 & -34.3 & 0.057 & -59.9 \\
13 & 23 & 0.095 & - & 0.146 & 0.133 & -8.9 & 0.104 & -28.8 \\
14 & 25 & 0.039 & - & 0.099 & 0.088 & -11.1 & 0.053 & -46.4 \\
18 & 27 & 0.049 & - & 0.073 & 0.097 & 32.9 & 0.062 & -15.6 \\
29 & 17 & 0.188 & - & 0.137 & 0.203 & 48.2 & 0.150 & 9.5 \\
\hline 23 & 31 & 0.025 & 10 & 0.080 & 0.083 & 3.8 & 0.040 & -50.5 \\
24 & 26 & 0.030 & 150 & 0.072 & 0.068 & 5.6 & 0.045 & -37.3 \\
25 & 24 & 0.076 & 10 & 0.161 & 0.131 & -18.6 & 0.087 & -45.9 \\
26 & 24 & 0.076 & 70 & 0.124 & 0.128 & 3.2 & 0.087 & -29.8 \\
27 & 15 & 0.139 & 10 & 0.213 & 0.189 & -11.3 & 0.147 & -31.0 \\
28 & 13 & 0.235 & 10 & 0.286 & 0.230 & -19.6 & 0.150 & -47.6 \\
\hline
\end{tabular}

Table 2: Data and results of experiments by Fauchart and Cortini [2], the numerical model, and Eurocode 2.

\begin{tabular}{ccccccccc}
\hline & $f_{c}$ & $\Phi$ & $u$ & \multicolumn{2}{c}{ Experimental } & \multicolumn{2}{c}{ Numerical } & \multicolumn{2}{c}{ Eurocode 2 } \\
Specimen & {$[\mathrm{MPa}]$} & {$[-]$} & $\mathrm{mm}$ & $\tau / f_{c}$ & $\tau / f_{c}$ & Error [\%] & $\tau / f_{c}$ & Error [\%] \\
\hline 5 & 20 & 0.049 & 10 & 0.106 & 0.088 & -17.0 & 0.057 & -46.3 \\
6 & 20 & 0.049 & 10 & 0.085 & 0.088 & 3.5 & 0.057 & -33.0 \\
7 & 20 & 0.096 & 10 & 0.120 & 0.126 & 5.0 & 0.099 & -17.3 \\
8 & 20 & 0.246 & 10 & 0.197 & 0.206 & 4.6 & 0.100 & -49.4 \\
9 & 20 & 0.047 & 10 & 0.104 & 0.086 & -17.3 & 0.055 & -47.0 \\
10 & 20 & 0.096 & 10 & 0.148 & 0.126 & -14.9 & 0.099 & -32.9 \\
11 & 20 & 0.096 & 10 & 0.148 & 0.126 & -14.9 & 0.099 & -32.9 \\
12 & 20 & 0.191 & 10 & 0.208 & 0.186 & -10.6 & 0.100 & -52.2 \\
\hline
\end{tabular}

